\title{
Higher Order Thinking Skills (HOTS) and Their Contribution to Turning the Teaching of Arabic Reading Comprehension into a Meaningful Process.
}

\author{
Rima Abu Jaber Baransi \\ Rawya Jarjoura Burbara \\ Oraninm Academic \\ College for Education- Israel
}

\begin{abstract}
This study discusses the incorporation of thinking strategies of high order in teaching in general and in the teaching of theoretical texts in particular. The main goal of the paper is to discuss the difficulties of teaching theoretical texts to students, but also present teachers with a tool kit when facing these difficulties. The present study lays the foundations for the teaching of a theoretical text, and suggests an efficient teaching method that will allow students to fully and thoroughly understand a text.
\end{abstract}

\section{Introduction}

In a globalized, technological era, and in light of the changes and developments of the $21^{\text {st }}$ century, many scholars emphasize the shift in the education system. While previous strategies positioned the student in the center, as a receptor of information from the teacher, current strategies consider teaching as a pedagogic dialogue between teacher and student and between student and studied material. Another important shift is from the constant search of knowledge and achievements into a process of imparting skills. It also became apparent that there is no one single answer for every question, but various dilemmas with no clear answers.

In terms of teaching and education, thinking is a critical factor for meaningful learning; it contributes to the deep understanding of studied contents, for the cultivation of a high cognitive ability in various aspects and contexts, as well as the development of critical and creative thinking.

Teaching thinking skills is an educational movement aiming at replacing a prevailing teaching method based on the transmission of information and its memorization with a different method, focusing on the developments of thinking skill of students, in school or in any other educational frame. Such an approach will turn students from passive consumers of information into creators of new contents and new knowledge, who impact the world beyond the school's walls. "[E]ducation for thinking is not only an intensive continuation of the traditional intellectual education; it differs from it in its focus: the focus of the intellectual education is 'inner value' texts that the very encounter of such texts is supposed to develop thinking. The focus of thinking for education is the development of thinking processes. Intellectual education teaches what to think; thinking education teaches how to think". (Harpaz, 2000). However, with the growth in knowledge, students need skills that will allow them to cope with the studied material independently. They also require skills that will help them face their changing world and complicated assignments that demand creativeness and critical thinking.

\section{Literature Review}

Higher Order Thinking is considered to be an ambiguous meta-term. There are several approaches for the classification of thinking levels, the earliest common is Bloom's taxonomy of learning domains starting from the simplest to the most complex: knowledge, comprehension, application, analysis, synthesis and evaluation. Hanna \& Michaelis were the first to understand Bloom's original aim but suggested a different scale, starting with low order thinking to higher order thinking in the following manner: observing, remembering, explanation/interpretation, comparison, classification, generalization, conclusion, analysis, synthesis, raising hypothesis, prediction and evaluation (Hanna \&Michaelis). Based on Bloom's taxonomy, Newman differentiates between Higher Order Thinking and Lower Order Thinking arguing that Higher Order Thinking is "complex and challenges the learner into interpretation process, analysis and engagement with information", while lower order thinking includes basic skills of collecting information and its classification (Newman, 1990). Passig suggests yet another adaptation to Bloom's taxonomy, adding a seventh level, melioration, that is: "[T]he skill to choose the appropriate aggregate of information, and to implement it in solving problems in different situations, times and places, thus meliorating the aggregate" (Passig, 2001). 
Krathwol's adaptation to Bloom's taxonomy suggests six affective domains of thinking: knowledge of facts, conceptual knowledge-terms; procedural knowledge - mostly of process; meta-cognitive knowledge (Krathwol, 2002).

Resnick adds the self-regulation of thinking process as one of the characteristics of higher thinking order (Resnick, 1987). Zohar builds on Resnick's conceptual framework, and describes higher order thinking as "associated with problem solving skills, asking questions, critical thinking, making decisions and taking responsibility. Making decisions is a critical factor in solving problems stemming from the gap between preliminary situation and the end goal, when there is no one clear solution" (Zohar, 1996).

As is already apparent, there are significant disagreements among scholars regarding the definition of "higher order thinking"; nonetheless, there is a common acceptance that "it is the ability to fully utilize information and produce beyond what meets the eye, it is the adoption of a critical approach to evaluate information and process, to develop meta-cognitive awareness and problem solving skills. The ability to think independently and the ability to make decisions using one's own judgment are required for optimal performance in the present millennia" (Glesner; Ben David; Iger, 2009).

Higher Order Thinking encompasses various skills, including problem solving, asking questions, critical thinking, decision making and taking responsibility.Therefore, it needs to be integrated in all content subjects. Forster emphasizes that higher thinking order is part of higher learning order; it is comprised of five points: communication, personal development (personal future), social responsibility, the world's future and developments thinking (Forster, 2004). When discussing higher order thinking, we are actually discussing four issues: thinking strategies, thinking process, thinking language and meta-cognition. ${ }^{1}$

The integration of higher order thinking in learning develops students' intelligence and allows them, according to Resnick, to acquire stamina and consistency when searching for in a particular content subject. They learn to get to know themselves as learners; they also perceive the veryessence of their understanding and their knowledge in the various disciplines as well as the scope of their abilities and skills. Instead of being informed with the facts, students acquire the ability to solve problems, make judgment and take decisions. Perkins \&Ritchhart entitled higher thinking order as good thinking. They presented three major aspects including: sensitivity, i.e., "whether a person notices occasions in the ongoing flow of events that might call for thinking". Inclination, that is the investment of direct effort in thinking an issue through, this inclination stems from curiosity, one's background, habits of the mind and more. Ability concerns the logical use of thinking capabilities (Perkins \&Ritchhart, 2004). These features alongside skills such as inclination to teamwork, organizational and thinking skills, the ability to think critically and creatively are essential for the development of a meaningful career in the $21^{\text {st }}$ century.

\section{ICT Computer Assisted Instruction and Higher Order ThinkingSkills (HOTS)}

In recent years, the computer has become the infrastructure/foundation for learning and higher thinking order. The computer is the main tool that allows an adult to intelligently overcome daily assignments and problems. for students, computers are a tool that helps organize information, and eventually helps them to turn information into problem solving knowledge (Solomon, 2000; Dede, 2007; Eshet, 2004; Hay, 2001).

The use of computers and technology in general, develops higher thinking in learning process. According to McMahon, the amount of time dedicated to learning using a computer has a positive effect over critical thinking and creative thinking performance. McMahon also demonstrated that students who learned using computers scored higher in assignments assessing critical and creative thinking (McMahon, 2007). Therefore, it is important to incorporate technology in all disciplines

Therefore, the use of technology, the integration of computers and the Internet in the classroom, develop thinking and lead to meaningful learning. Meaningful learning allows for information processing and thus, to enable higher thinking order and complex analysis of information.

\section{Meaningful Learning Programs}

A meaningful learning program is a constructive program in which knowledge is built in a spiral form, and is based on operative and measurable goals. It is a program that suggests different methods and alternative ways for teachings and evaluation instead of restricting teachers into particular contents. A meaningful learning program provides the basis for teaching and enables more freedom in choosing appropriate contents for target audience: learning community, investigating community, knowledge-building community and thinking community.

${ }^{1}$ http://www.azrieli.org/userFiles/files459/bg83an49.pdf 122 
Digitization enhances students' interest as well as their engagement with the learned material; it also opens a wide array of knowledge right in front of the student. Thinking strategies are the tool through which a student is to absorb and comprehend this flux of information. Most students lack this basic tool as well as basic development of interests, learning languages, thinking methods and basic education (Gordon, Sharon, 2008). Meaningful learning will aid students to master terms, languages and typical thinking process.

\subsection{Role of the Teachers}

Teachers have an important and central role in the developments of a meaningful learning environment, that invites higher thinking order and enables creativity on the part of the learner. Teachers' expectations, the guidance they provide students, proper planning of lessons and their companionship are necessary conditions for meaningful learning. "Teacher's awareness to the need in the cultivation of thinking is a necessary condition for the very existence of a productive and interesting learning process" (Zohar, 1996). It is significant that a teacher offer the appropriate conditions for thinking in each lesson, such as: the construction of a lesson plan that incorporates difference disciplines and establish high levels of enquiring.

Beyer argued that teachers' main role is to improve learners' quality of thinking and to teach them how to efficiently, productively and consciously use it (Beyer, 2001 a). He also discussed the fruitful association between thinking and different disciplines: the cultivation of thinking skills improvesachievements and motivates into thinking (Beyer, 2001).

\subsection{A Theoretical Text}

The theoretical text is a non-fictional text, and it is also called an expository text. Such texts may provide information, criticism, or theory. Theoretical texts are found in encyclopedias, journals, professional literature and manuals. In newspapers, one may find political texts, texts discussing economy as well as texts analyzing a literary creation or a sport event.

The main purpose of a theoretical-educational text is to define, explain, elaborate and expend the various meanings of terms, phenomena and process in the world, to inform about people and events. Therefore, it is of great importance to teach our students how to approach a theoretical text. This skill will help them understand the world and live in a literary society that requires its members to read, understand and write. Our students are exposed to fiction and to artistic texts ever since they are toddlers, and only afterwards are they introduced to theoretical texts. The reason for that is the complexity of theoretical texts, and since they are much harder to understand and allow access to a whole world of information, they also provide access to a normative world of terms and unfamiliar logical structures. The theoretical text also introduces students to new vocabulary, raises curiosity and opens a window to new fields of interest.

\section{Research Questions}

The study poses three questions and tries to find answers to them:

- How do we turn the learning of a theoretical text into a meaningful learning?

- How does the incorporation of Higher Order Strategies contribute to the understanding of a text?

- What is the contribution of ICT learning/computer-assisted instruction in teaching Arabic language?

\section{Hypothesis}

- The incorporation of Higher Order Thinking Strategies in the teaching of theoretical texts is an important tool for the understanding of the text.

- The integration of digital pedagogy in the teaching of a theoretical text positions the learner in the center and turns the passive learner into an active learner.

- The level of atext should be matched to the target audience; nonetheless, the teaching method should be the main criteria, rather than the audience. The teaching method allows students of different levels to understand even difficult texts.

\section{Methodology}

The study adopted the quantitative qualitative methodology.The research tools consist of the following types: $a$ theoretical text, an opinion paper, and an exam (evaluation tool)

\section{Participants}

The text was introduced to several groups of participants: students in junior high, teachers of different disciplines attending a seminar/course/lecture, lecturers in an academic institution (Sakhnin College), and B.A. students in Oranim College during the course "Active Skills" taught by one of the authors of the present study. 
The chosen groups demonstrated great diversity in levels of individuals/subjects in each of the groups; the groups were heterogeneous and included learners of different levels. Additionally, teachers of the texts were interviewed.

\section{Variables:}

- Independent Variable: the text, method of teaching, evaluation sheet.

- Dependent Variable: level of learners.

\section{Materials of the Study}

\subsection{Text Description:}

The text is an argumentative opinion essay entitled: "Damascus in Search after its Identity in a Forest of Cement", authored by the Syrian author, Khalil Swilah.

10.2 Contents and the structure of the text: the argumentative essay is an essay that isdesigned to discuss and defend a position. The structure of such texts is of four parts: introduction, argument, justification and conclusion. The opening remarks include a quotation of the medieval historian Yaqut al-Hamawi (1179-1229), who describes Damascus as a heaven on earth. The second paragraph surveys the various conquerors of Damascus, and the rulers who left their historical imprint on the city. In each of the following paragraphs (third, fourth and fifth) the author presents a reason that contributed to the loss of the city's unique character. The last paragraph is a summary of the author's opinion and a demonstration that today's Damascus has already lost its historical identity and has become a forest of cement.

10.3 The Style of the text consists of opinions, proofs, demonstrations, contradictory opinions and conclusions. The Vocabulary consists of an average of over $5 \%$ new words for each group.

\section{Procedure}

The authors of this study were chosen to examine the incorporation of Higher Order Thinking Strategies in the teaching of a theoretical text. One of our main goals was to demonstrate to thestudents that the Arabic language is a living language, capable of changing and integrating diversity and modifications. In addition, we aimed to provide teachers with strategies for effective teaching methods of a theoretical text in a short time period.

\section{Results/ Findings}

The significance of the paperlies in providing teachers with methods and strategies for the teaching of a theoretical text. These strategies make learning more efficient and ensure that most of the information in the text will be clear. Our findings prove the effectiveness of Higher Order Thinking Strategies; students expressed their interest in the learned subjectthey take an active part in the process of learning by searching, experiencing, making their own associations with other disciplines and previous knowledge. All these experiences make the learning process meaningful and effective. In addition to direct knowledge and experience in learning a particular text, the students also receive a tool that will help them when they face similar texts. Such a tool helps students not only in the classroom, but also in their daily life.

The process of discovering and the personal experience of students stands in contrast to the standardization and grade industry and sense of alienation. Meaningful and qualitative teaching and learning process allow for the new knowledge to be imprinted in the student's mind for a long time. Furthermore, and perhaps most importantly, students acquire a toolkit for future experiences and future readings of different texts.

\subsection{Description of the Teaching Method}

Understanding a text depends on several variables:

- Correct reading of words, terms, idioms and sentences.

- Coherence of texts

- New/unfamiliar words should not amount to more than 3\%-5\% of the entire word count.

- Previous knowledge.

Giving these variables, we had to begin with a general introduction to the subject.

\subsection{First Part}

Starting with the title: "Damascus Searches for its Identity in a Forest of Cement" (دمشق تبحث عن هُويّة في غابة الإسمنت) We posed several questions intended to raise the students' interest and lead them to draw conclusions:

- What does the expression "forest of cement" actually mean?

- What kind of association do you have when you read this expression?

- Where is the "forest of cement"?

- Do you have any expectation as to the contents of the text in light of its title? 
- How can the identity of a city be defined?

Once the questions were posed, all answers were written down, and the floor was open for discussion among students. The next phase was to draw conclusions.

a. First conclusion: the forest is not a real forest; it doesn't really exist, rather, it is a metaphoric expression intended to present a particular stance.

b. Second conclusion: the author expresses a particular standpoint; therefore, we assume this is an argumentative essay.

c. Third conclusion: the title states that Damascus searches for its identity. Thus, it seems reasonable to assume that currently, Damascus is a state of lost identity.

Following this discussion, the students were asked to associate the title with their own life experience; they were required to present the identity of a city or a village they are familiar with. They were also asked whether Nazareth, Haifa and Jerusalem have their own unique identity. Eventually the whole class understood what the phrase "identity of a city" means.

"Reaching conclusion is the last phase in a thinking process, which brings about the creation of new information as a result of an analysis of previous information through information processing. The conclusion is the outcome of the concluding process and is generally phrased. The conclusion relates to all that is obligated as a logical inference drawn based on the accumulated facts through data collection process." (Kaniel, 2006)

\subsection{Second Part}

Before reading the text, students received preliminary information intended to facilitate reading. Already the second paragraph contains some new information that is difficult to absorb. This new information inhibits information, brings about boredom leading to alienation and disinterest on the part of the students. Therefore, we decided to make use of two teaching strategies, even before introducing students to the text.

\section{a. First Strategy: Tangible Information:}

Since students usually find abstract thinking extremely difficult, and have little experience in transforming the abstract into tangible information, we wished to make abstract data into tangible (and therefore useful) information. For instance, we changed names with photos found on Google Image and applied Higher Order Thinking Strategies with the students. We also asked the student to compare. They were asked to match between the picture and a name they see on the computer screen, and they connoted previous acquired knowledge and the information they were being introduced to in order to connect between a name and the appropriate picture. In case there is no computer in class, teachers may write names on the blackboard and make copies of photos. The students were divided into heterogeneous groups where they discussed and matched between a name and a photo. The additional value in ICT learning/computerassisted instruction is the ability to work independently, to search on their own information and to follow their interests.

Before continuing with the reading, we compared between pictures presenting "ancient Damascus" and "new Damascus". The tangible comparison between the two representations of Damascus, clarifies the students with the subject of the text and emphasizes that the author wishes to persuade us that Damascus lost its historical identity.

At this point, the students should read first and second paragraphs that comprise of a whole page. The First Paragraph is a quotation of a medieval text. The quotation presents Damascus as heaven on earth. The author mentions the abundance of trees, waters, gardens and so on.

The Second Paragraph surveys the various cultures whose presence left an imprint on the landscapeof the city. The students encountered names they were already familiar with, transferring them from abstract into tangible information, hence the once difficult and obscure text was elucidated. At this point, the students acquired yet another important strategy: classification, a strategy needed when confronted with a large amount of data.

b. Second Strategy: classification is a Higher Order Thinking Strategy; findings were classified according to criteria decided upon by each of the groups. Most groups decided to classify chronologically. For instance, Umayyad period Great Mosque of Damascus, Byzantine period - mosaic etc. After classifying, the students created a table, and created a set of criteria intended to help them sort out the information.

c. Third Strategy:drawing conclusions and synthesis

At this time, students face yet another packed and difficult page to go over. As teachers, we need to bear in mind that the amount of material students face had a significant effect on their capacity to contain and absorb. The Second Page is divided into three paragraphs, each presenting a reason for Damascus' becoming a forest of cement. We asked the students to draw conclusions, based on their reading, and to identify through the method of "cause and effect" the reasons that brought about the outcome of building high buildings in Damascus. Learners are expected to use two high order strategies: drawing conclusions and synthesis. 
The students were required to draw a conclusion from each paragraph and then to merge three conclusions into a coherent phrase(s). The accumulation of information from the three paragraphs necessitates creating associations between terms, and the understanding of causality relations between the various events or developments. ${ }^{2}$ This is achieved through a Power-point presentation and ICT learning/computer-assisted instruction, which keepsthe students active and involved in the process of learning, cooperating and eventually understanding the text.

\section{d. Fourth Strategy}

In the last part, the students take up a comparison strategy once again. However, this time, they compare between opinions expressed by two different authors: Yaqut al-Hamawi, who described Damascus as a heaven, and Khalil Swilah, who argues that Damascus is no longer a paradise, but rather a forest of cement. Using a computerized table, the students need to write down three reasons that support Yaqut's opinion, and three reasons that support Swilah's. This table is intended to help learners understand.

To sum up this part, the students not only understood the text, identified its genre and its purposes, but they also, perhaps more importantly, acquired a toolkit that helped them when reading any other text in the future. Moreover, they were able to do so without the help of a teacher or a guide.

The students were introduced and made use of the following skills and strategies:

- Making the abstract tangible; this strategy is used when confronted with new information

- Classification: this strategy is used when there is a significant amount of information and in need of a tool to put it in order.

- Comparison strategy: it isused when in need of differentiating between different positions.

- Drawing conclusion strategy: it isused while processing information, analyzing previous knowledge and the creation of new knowledge.

- Digital pedagogy: ithelped us in finding new information, comparing it to previous knowledge, making the abstract tangible and engaging young students with scientific thought.It also helped in providing answers to students of different levels, and promoted cooperation between themembers of each group.

\section{Discussion}

In this section, we present the findings of our study, addressing them from different angles. We discuss our initial hypotheses and whether or not they were substantiated. We also relate to the dependent and independent variables and their impact on meaningful learning:

Independent Variable: the text, method of teaching, evaluation sheet.

Dependent Variable: level of learners.

\section{- Independent Variable:}

1. The text: as already mentioned, the text is an argumentative essay, written in a characteristic format. The understanding of the structure of the text is inseparable from the understanding of the contents of the text. Once a student understands that $\mathrm{s} / \mathrm{he}$ is reading an argumentative essay, s/he will begin their reading searching for the author's opinion, identifying examples, arguments and proofs provided in support of the presented opinion. They will also be able to identify the opposing opinion (in case the author mentions it) as well as the summary.

In other words, understanding the structure is the first step in understanding the text, since readers are trained in locating relevant parts of the text. For instance, if astudent reads a story, s/he will be able to find and identify the important component of the story such as time, place, plot and figures.

Therefore, the first tool we transmitted to students was the contextual relation between the genre and its structure and format as well as the relation between understanding the structure and reading comprehension.

2. Teaching method: aiming toward meaningful learning positions the student as the agent of learning. Thus,the students went through three most significant phases in meaningful learning: experiencing, discovering and associating. The students had to independently search for cause and effect, synthesize information retrieved from different sources, associate between name and picture, discover the common and the difference. All these actions helped the learners to organize information allowing easy access to it when in need.

Of significant importance is yet another teaching strategy, which is: making the abstract tangible; we made sure that all the new and unfamiliar information is tangible and concrete. The students were active in the process of acquiring the

\footnotetext{
${ }^{2}$ Ministry of Education, section for the planning and developing study programs (2009). Higher order thinking strategies. A guiding document for authors of national teaching programs and developers of learning material.

126
} 
information.For instance they were involved in searching for date, related names to the correct picture using hint and associations.

For instance, though they may never have heard of Salah al-Din al-Ayyubi, yet, they know they are looking for Salah al-Din's fortress, they will search for a picture with a fortress or a monumental building and discuss among themselves which of the mentioned structures could be depicted in the particular picture. They debated whether it is a fortress or a castle, and if a fortress, is it Salah al-Din's or is it Jupiter's fortress. Thus, while they never visited or saw a picture of either building, the process that led them to identify each of the structures made their knowledge concrete as well as meaningful.



Fig. 1 Salah al-Din's Fortress

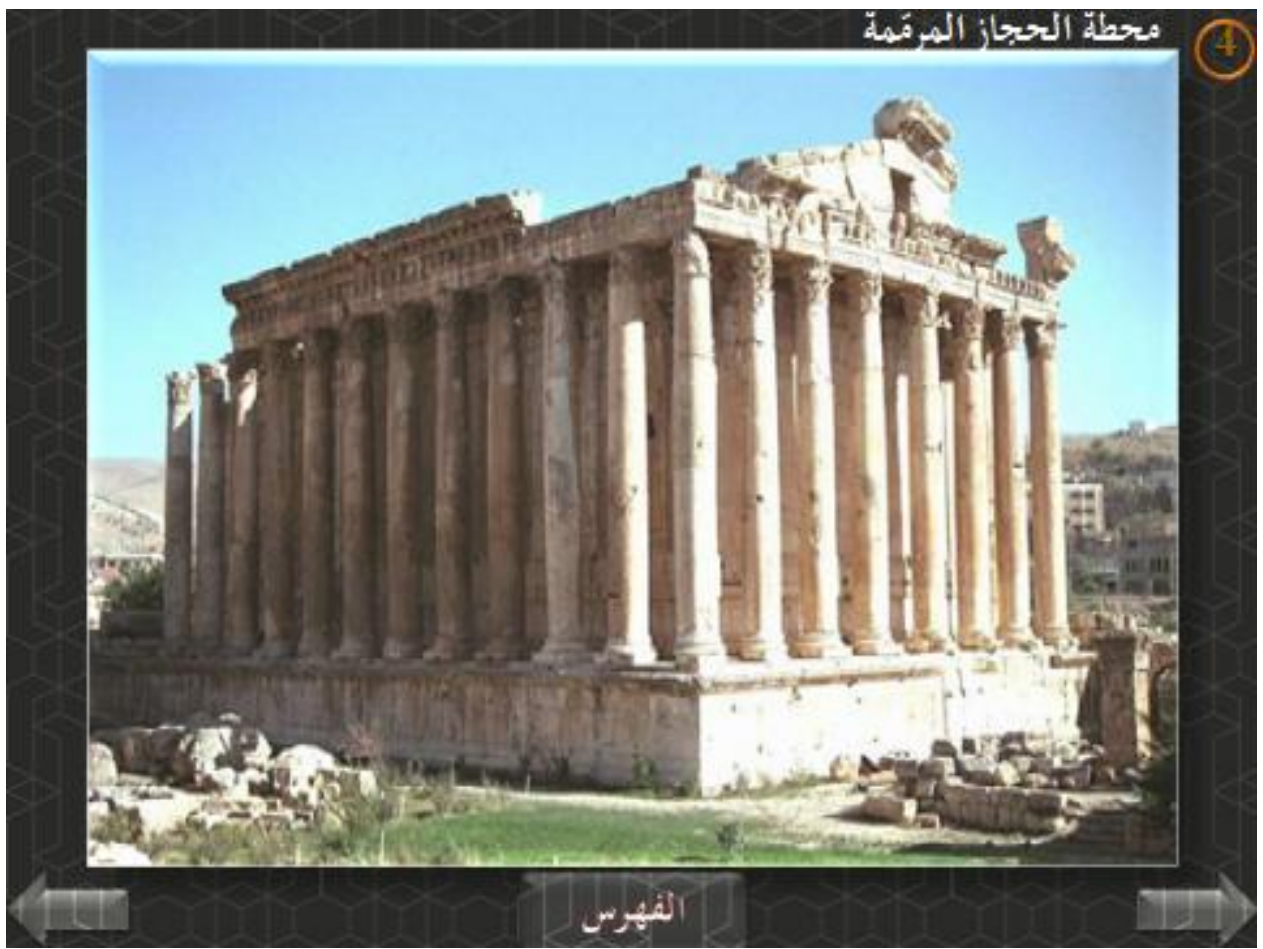

Fig.2 Balbak Castle in Lebanon

Pictures streamed on the computer screen in front of the students; there was also a list of names of buildings. The students had to match the title Old Train Station "al-Hijaz" to the correct picture, they chose: 


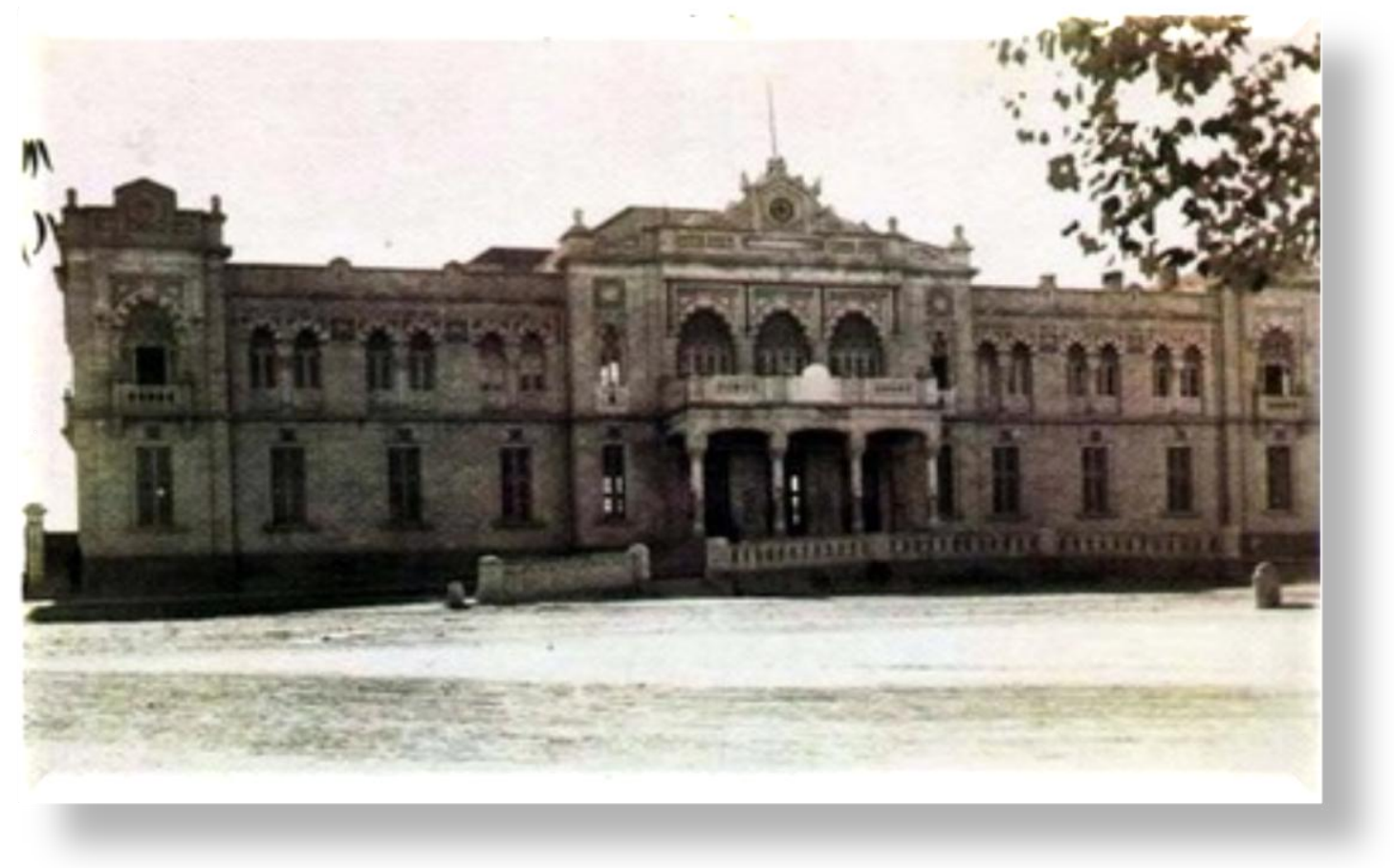

Fig. 3 al-Hijaz Train Station

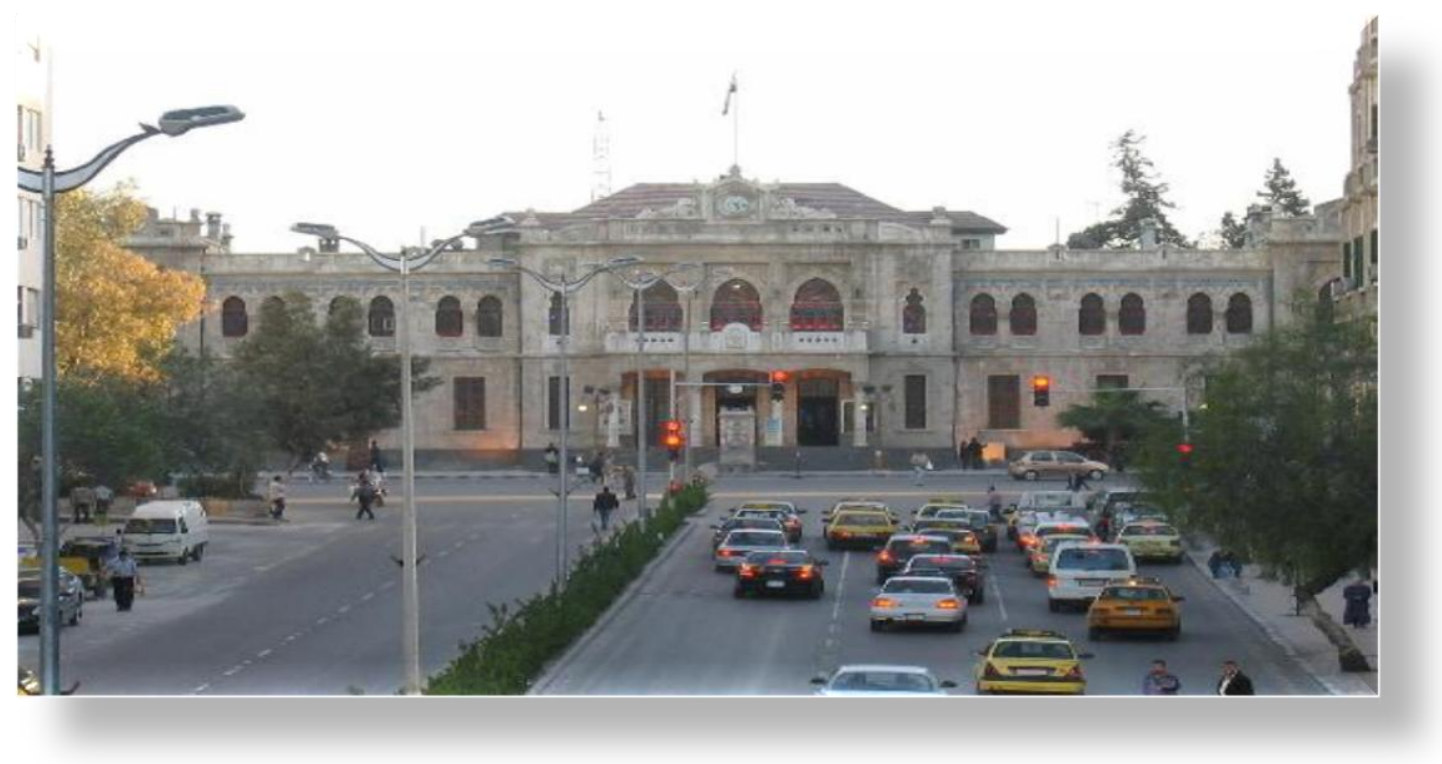

Fig. 4The Train Station building today; the site was transformed into a taxi station serving the Damascus-Beirut line. After identifying and matchinga picture to a name, the students had to compare the old and new building. This comparison demonstrated what the title hinted at, how a city or a country can lose its identity.

The implementation of these strategies allowed forstudents to be actors and creators of knowledge rather than memorizing it, and active rather than passive. The students take an active part in the process of learning; they investigate independently, read and in general take control over the learning process. All these activities lead to fulfilling, effective and beneficial learning process.

Integration of Higher Order Thinking Strategies was an important tool not only for the process of learning but also for the final outcome: understanding the text.

The students learned that when facing a difficult text, packed with details and information, they should employ classification strategy. 
Drawing conclusion strategy was used throughout the process, starting from reading the title and attempting to understand its meaning, to the last parts of the essay. The students were asked to write down their conclusion(s) after each part, activity or discussion.

Synthesis of information strategy helped to summarize the causes and effects. The students had to extract one cause leading to one effect in each of the paragraphs. Synthesis of the various outcomes illustrated the changes Damascus had gone through until the present.

Comparison strategy was implemented when the students were asked to match names to pictures and when compared pictures of the same building in different times. They compared illustrations of green and blooming ancient Damascus, to modern Damascus that has lost its identity and became a city of high buildings and constructions.

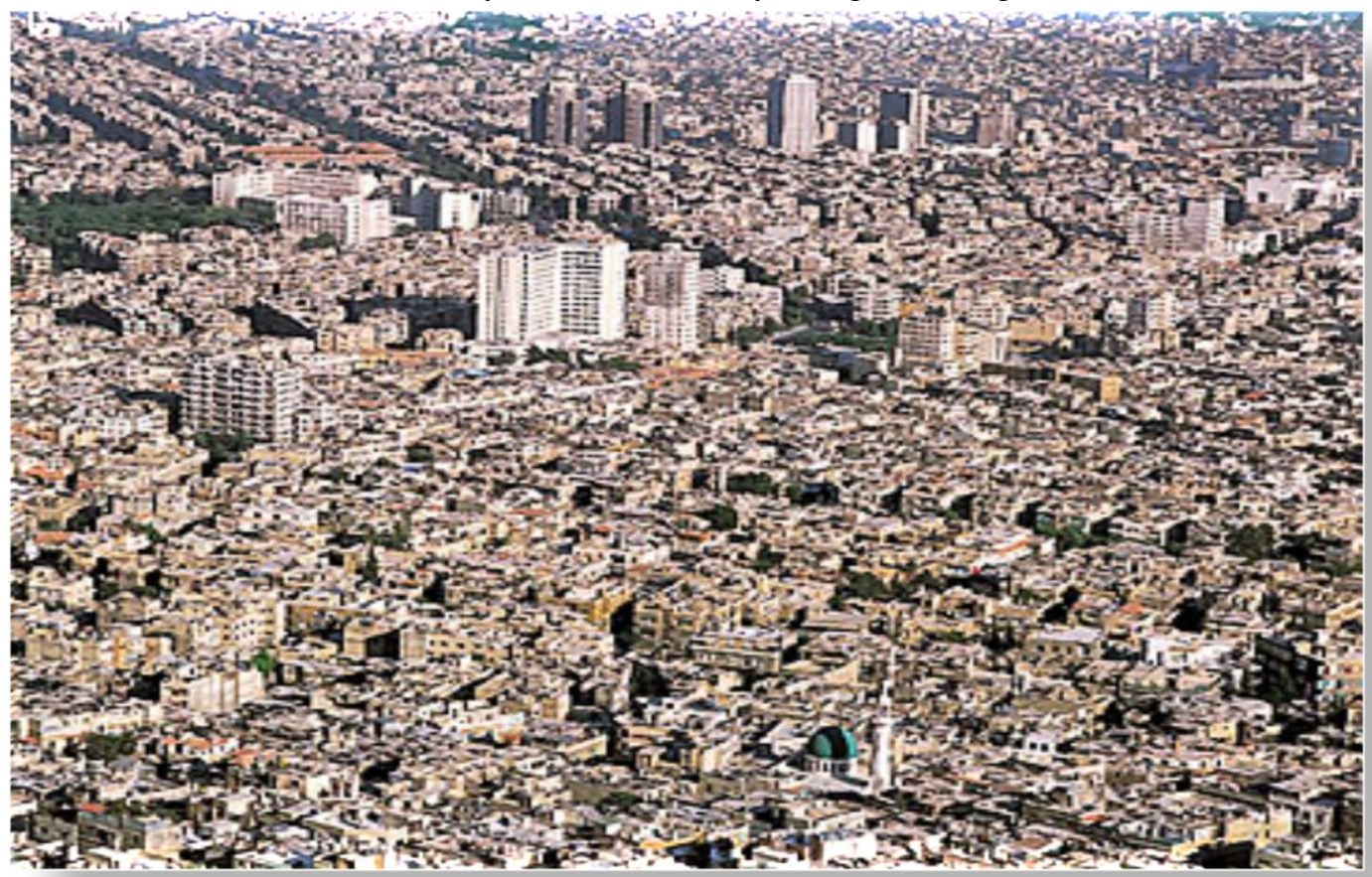

Fig. 5 Damascus today, a city that has lost its identity.

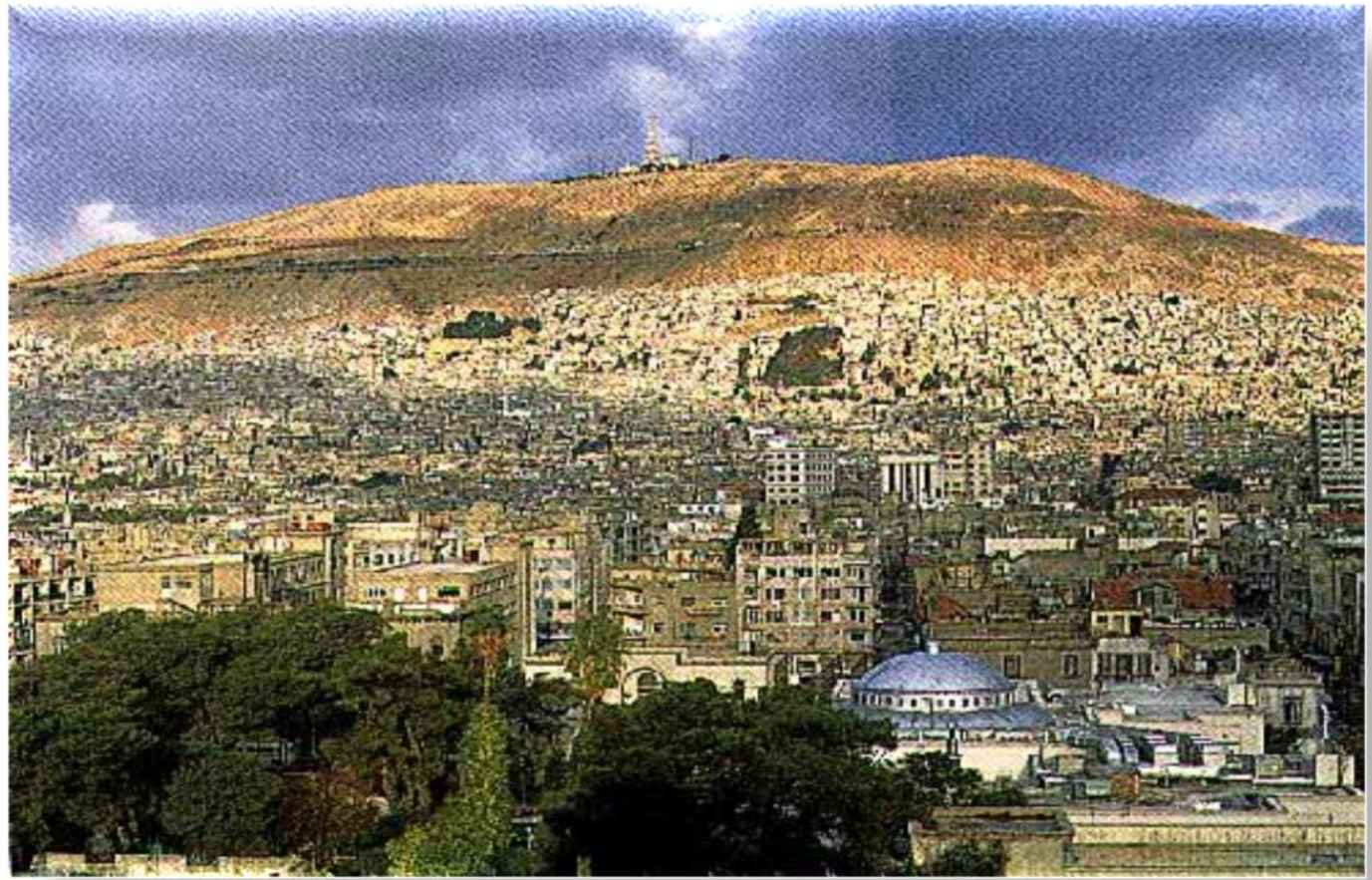

Fig. 6 Ancient Damascus. 
The students compared the two pictures in terms of view, scenery and monumental structures visible in the skyline. For instance, Mount Qasioun, which ruled the skyline in the ancient city picture, has been covered by high buildings. Students could actually see the forest of cement; hence, the author's argument became concrete and understandable.

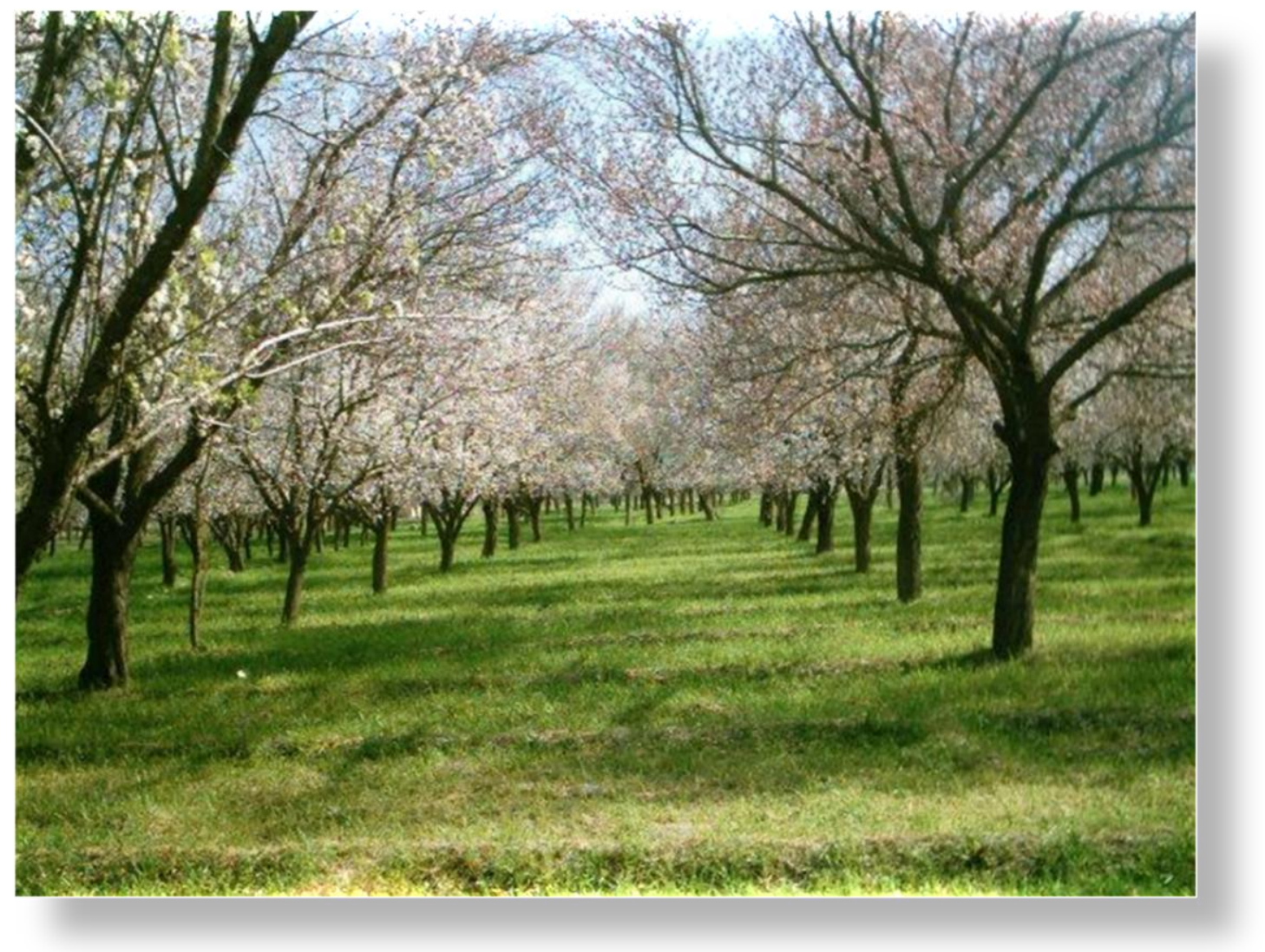

Fig. 7 al-G'utta

All the students associated between fig. 7 and al-G'utta, a place familiar from Syrian televised series describing life in pre-modern Damascus.

Using tables, maps and flow charts helped the students to put information in order (thinking organizers). Moreover, these tools helped the students tounderstand, remember and focus, and, when in need, to fill in the correct data.

\begin{tabular}{|l|l|}
\hline Cause & Effect \\
\hline Immigration from rural areas to the capital & Many houses scattered without any order \\
\hline $\begin{array}{l}\text { The program planned by the French engineer } \\
\text { Ecochard }\end{array}$ & Housing complexes and high buildings \\
\hline $\begin{array}{l}\text { TheUnited Arab Republic (apolitical union } \\
\text { between Syria and Egypt) }\end{array}$ & $\begin{array}{l}\text { Immigration to Beirut and the construction of } \\
\text { many buildings }\end{array}$ \\
\hline
\end{tabular}

Another possible table is a table comparing between Yaqut al-Hamawi's depiction of Damascus and the author of the text, Khalil Swilah's depiction of the city. This table included citations from the text in a table.

\begin{tabular}{|l|l|}
\hline Damascus is a paradise & Damascus is not a paradise \\
\hline & \\
\hline & \\
\hline
\end{tabular}

The students were given awork sheet that served as a basis for deciphering their findings. The Questions were of four facets of understanding:

Literal, local understanding: understanding the word out of its context, locating information explained in the test, reconstructing a text, retrieving previous knowledge relevant to the text, understanding the relation between the different parts of the text. 
Inferential, global understanding: drawing conclusions, creating generalization, identifying the author's position, understanding main idea or argument presented in the text.

Evaluative: differentiating between fact and opinion, raising hypotheses, understanding the goals of the text, expressing a clear opinion regarding the text, multi-dimensional thinking, identifying points of view.

Meta-textual knowledge: understanding rhetorical tools, understanding images and metaphors, meta-lingual understanding.

\section{- Dependent Variable: level of students}

The introduction states that the text was taught to four different groups. In order to prove the effectiveness of meaningful learning to a wide range of audiences, we chose four different levels of learners. We wished to demonstrate that the level of the text should not be the cause, or the main cause to lack of understanding. Rather, the teaching method is the crucial factor deciding whether or not a student/reader understands the text.

\section{Focus groups:}

- Eighth and ninth graders of different schools.

- Third year students in various colleges, studying to be Arabic and early childhood teachers.

- Teachers of various disciplines (history, geography, mathematic, etc.) who teach in Arabic.

- Lecturers of different disciplines in one of the colleges,

- All the learners went through a similar process of learning, but they differed from one another in their pace, participation, answers, and interest.

- Interviews conducted after the learning process raised several findings:

- Group of teachers actually adopted the method and used it in their classrooms, each in his/her discipline. The teachers reported a significant change in students' interest and success.

- Lecturers in college reported this was the first time they encounter a lesson in Arabic that stimulates them and turns them into active participants. Prior to the process, they were sure they were about to be in yet another boring text analysis lecture, that they will have nothing to say and that they will be completely passive as they are not Arabic teachers. However, after taking part in the process, some said they found the lesson beneficial, and even enjoyable to some extent. Furthermore, some said they will adopt the method demonstrated in their college lessons.

- Students in college said that the lesson was so much fun and so interesting, that they were willing to take a two hours'commute, in bad weather conditions, just to be part of the lesson. They also said they will implement this teaching method once they become teachers.

- Junior high students were satisfied and said that they were worried before starting the learning process. They were concerned about the amount of material they will have to learn, from the subject of the essay and the huge amount of information they were expected to absorb. However, they all agreed that the teaching method helped a lot, not only in understanding the text, but also in acquiring a whole toolkit, they will carry and use when facing other texts.

\section{Conclusions}

There is no doubt that digital pedagogy had significant beneficial impact on the process of teaching and learning for each of the groups. Digital pedagogy had additional benefits that traditional teaching that neither teacher nor book or a combination of the two could provide for the students.

ICTs allow great independence and self-realization to students. Furthermore, students are actively involved in the process of learning; they search the databases, compare information and draw conclusions. Most of all, students acquire a toolkit, they could carry around and use with future texts.

Our final activity included listening, and watching Nizar Qabani, reciting his poem "This Is Damascus" [هني دمشق]. The poet described his beloved city Damascus, the city of his youth, his love and longing to this Damascus. Later on, the students listened to the same poem, butthis time it was sung by the famous Syrian singer Asala Nasriat this stage. The students could compare and relate the contents of the text they learned and the poem they just heard.

\section{References}

Beyer, B. K. (2001 a). Developing a Scope and Sequence for Thinking Skills Instruction. In: A.L Costa (Ed.). Developing Minds. A Resource Book for TeachingThinking, 248-252. ASCD Publication.

Beyer, B. K. (2001 b). What Research Says About Teaching Thinking Skills. In: A.L Costa (Ed.). Developing Minds. A resource Book for Teaching Thinking, 275-282. ASCD Publication.

\footnotetext{
${ }^{3}$ https://www.youtube.com/watch?v=iEb717OgDkQ
} 
Coles, M. J \& W. D. Robinson (1991).Teaching Thinking: A Survey of Programs in Education.Bristol Classical Press, Great Britain.

Costa, A.L. (2006). Five Themes in a Though-full Curriculum. Thinking Skills andCreativity Journal 1, 62-66.

Costa, Arthur (1991). Toward a Model of Human Intellectual Functioning, Costa (Ed). Developing Mind: A Resource Book for Teaching Thinking. ASCD, Alexandria. Virginia, USA,.

Dede, C. (2007). Introduction: A Sea Change in Thinking, Knowing, Learning and Teaching. ECAR Research Study6, 19-26.

Eshet, Y. (2004). Digital Era. Journal of Educational Multimedia and Hypermadia, 13 (1), 93-10.

Forster, M. (2004). Higher Order Thinking - ACER, Research Development. Vol. 11, 10-15.

Glassner, Amnon, Ben David, Adi and Igger, Anat (2009). Developing Higher Order Thinking, Literary Survey. Ministry of Education: Department of Planning and Developing Teaching Program.

Gordon, David and Sharon, Dan (2006). Thinking of Secondary Education in Israel. Taub Center for Social Policy in Israel, Jerusalem.

Harpaz, Yoram (2008). The Third Model: Teaching, Learning in Thinking Community. SifryatPoalim.

Harpaz, Yoram (2014). Conditions for Meaningful Learning. Hed Ha-Hinukh Journal, 40-45.

Harpaz, Yoram (ed.) (2000). Educating Thought: Teaching and Learning in ThinkingCommunity: On Our Way to thinking School. Branco Weiss Institute, Jerusalem.

Hay. L. (2001) Thinking Skills for the Information Age. In: A.L Costa (Ed.) Developing Minds. A Resource Book for Teaching Thinking. ASCD Publication, 7-10.

Kaniel, Shlomo (2006). Educating for Thinking: Cognitive Education for the Control of Consciousness.Ra'anana: Ramot.

Krathwohl D.R. (2002). A Revision of Bloom's Taxonomy: An Overview. Theory and Practice. 41 (4), 212-217..

McMahon, G. P. (2007). Getting the Hots with what's in the Box: Developing Higher Order Thinking Skills within a Technology-Rich Learning Environment. Thesis for Doctor of Philosophy. Curtin University of Technology.

Newman, F.M. (1990). Higher Order Thinking in Teaching Social Studies: A Rationate for the Assessment of Classroom Thoughtfulness. Journal of CurriculumStudies, 22, 41-56.

Passig, D. (2001). A Taxonomy of ICT Mediated Future Thinking Skills. In: H. Taylor Hogenbirk P., (eds.), Information and Communication Technologies in Education: The School of the Future, (pp. 103-112). Kluwer Academic Publishers, Boston.

Perkins, D. \&Richhart, R. (2004). When Is Good Thinking? In D. Y. Dai. R.J. Sterenberg (eds.), Motivation Emotion and Cognition. Integrative Perspective on Intellectual Functioning and Development, 351-384. London: Lawrence Erlbaum.

Resnick, L. (1987). Education \& Learning to Think. Washington D.C: National Academy Press.

Solomon, G. (2000). Technology and Education in the Age of Information. University of Haifa and ZmoraBitan, Haifa. Zohar, A. (1996). To Learn, to Think and the Learn to Think.Branco Weiss Institute, Jerusalem. 